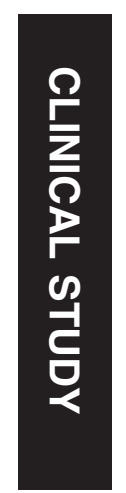

${ }^{1}$ Southern California Desert Retina Consultants, Palm Desert, CA, USA

${ }^{2}$ Loma Linda University, Department of Ophthalmology, Loma Linda, CA, USA

${ }^{3}$ Black Hills Regional Eye Institute, Rapid City, SD, USA

${ }^{4}$ Retinal Disorders and Ophthalmic Genetics, Jules Stein Eye Institute, UCLA, Los Angeles, CA, USA

Correspondence: CK Chan, Southern California Desert Retinal Consultants, PO Box, 2467, Palm Springs, CA 92263, USA

Tel: + 17603402394

Fax: + 17603225362

E-mail: CChan@

desertretina.com

Received: 8 July 2014 Accepted in revised form: 21 August 2014 Published online: 3 October 2014

Presented in part at the Annual meeting of the Association for Research in Vision and Ophthalmology on 2 May 2011, Fort Lauderdale, FL, USA; the Retina Subspecialty Day Meeting during the American Academy of Ophthalmology (AAO), 21 October 2011; and the Annual Meeting of the AAO, 25 October 2011, Orlando, FL, USA.

\section{Earlier therapeutic effects associated with high dose (2.0 mg) Ranibizumab for treatment of vascularized pigment epithelial detachments in age- related macular degeneration}

CK Chan ${ }^{1,2}$, P Abraham ${ }^{3}$, D Sarraf ${ }^{4}$, ASD Nuthi ${ }^{1}$, SG Lin' and CA McCannel ${ }^{4}$

\begin{abstract}
Summary statement Intravitreal high dose ( $2 \mathrm{mg}$ ) ranibizumab may lead to quicker resolution of choroidal neovascularization (CNV) and associated retinal pigment epithelial detachment in eyes with exudative age-related macular degeneration, although it may possibly correlate with RPE tears in certain cases.
\end{abstract}

Purpose This prospective study compared the outcomes of 0.5 vs $2.0 \mathrm{mg}$ intravitreal ranibizumab injections (RI) for treating vascularized pigment epithelial detachment (vPED) due to age-related macular degeneration.

Methods Patients with vPED were randomized to receive 2.0 vs $0.5 \mathrm{mg}$ RI monthly for 12 months or for 4 months and then repeated on a pro-re nata basis. Optical coherence tomography, fundus photography, and fluorescein and indocyanine-green angiography were obtained at baseline and subsequent specific intervals. Outcome measures were best-corrected standardized visual acuities, central 1-mm thickness, surface area (SA), greatest linear diameter (GLD), heights (PED and CNV), and amount of subretinal fluid (SRF) and cystoid macular edema (CME).

Results Both groups yielded reductions of the central 1-mm thickness, PED and CNV SA and PED height and GLD, SRF, and CME. Vision improvement and reduction in
SRF and PED height occurred earlier for eyes receiving the $2.0 \mathrm{mg}$ dose. Cataract progression was similar but RPE tears developed more often with the $2.0 \mathrm{mg}$ dose. Conclusions There were similar visual and anatomical outcomes at the end of the study; however, the higher dose yielded more rapid reductions and more complete resolution of the PED, although there was possible increased tendency for an RPE tear with the higher dose.

Eye (2015) 29, 80-87; doi:10.1038/eye.2014.233; published online 3 October 2014

Introduction

Prior studies showed retinal pigment epithelial detachment (PED) developing in more than $80 \%$ of eyes with exudative age-related macular degeneration (AMD); ${ }^{1-4}$ with $\sim 70 \%$ of the PED cases demonstrating vascularization. ${ }^{3}$ Such vascularized PEDs (vPED) have poor therapeutic response. 1,3,5,6 Pilot studies showed variable responses of vPED to anti-VEGF therapy. 1,7,8 The ANCHOR and MARINA studies demonstrated improved vision in eyes receiving monthly ranibizumab injections (RI). ${ }^{9-11}$ The HABOR Study reported equivalent visual and anatomical outcomes between high dose $(2.0 \mathrm{mg})$ and conventional dose $(0.5 \mathrm{mg})$ of ranibizumab for treatment of exudative AMD at 12 months. ${ }^{12}$ Stratification of lesion subtypes was not a part of 
these studies; therefore, its applicability to the more difficult-to-treat subtypes of neovascular AMD such as vPED is unknown. Recent studies evaluated the outcomes of ranibizumab for treating vPED due to AMD, but not comparing the results of various doses of ranibizumab. ${ }^{1,6-19}$ Our prospective study addressed the benefits and risks of 2.0 vs $0.5 \mathrm{mg}$ ranibizumab for treating vPED due to AMD on a monthly as well as pro-re nata (PRN) basis for up to 12 months.

\section{Material and methods}

This was a multicenter, randomized, prospective, openlabel pilot study. Eligible patients were randomized to receive one of four treatment protocols: Regimen (1) RI of $0.5 \mathrm{mg}$ monthly for 12 months, Regimen (2) RI of $0.5 \mathrm{mg}$ monthly for 4 months followed by repeat RI on a PRN basis for 8 months, Regimen (3) RI of $2.0 \mathrm{mg}$ monthly for 12 months, and Regimen (4) RI of $2.0 \mathrm{mg}$ on a monthly injection for 4 months followed by repeat RI on a PRN basis. The PRN criteria for Regimen 2 and 4 were the following:

(a) RI was continued if the macula was not completely flat on optical coherence tomography (OCT) (sensory macula and retinal pigment epithelium (RPE)).

(b) If macular flattening occurred, retreatment was allowed for the following: (i) loss of five letters on the Early Treatment of the Diabetic Retinopathy Study (ETDRS) chart compared with a prior visit; (ii) new or persistent subretinal fluid (SRF) or cystoid macular edema (CME) on OCT; (iii) New-onset or persistent choroidal neovascularization $(\mathrm{CNV})$, and (iv) new or persistent hemorrhage.

\section{Inclusion and exclusion criteria}

Eligibility criteria included: (i) age $\geq 50$, (ii) submacular vPED due to AMD (confirmed by fundus photography (FP), fluorescein angiography (FA), and OCT) (ii) PED measuring $\leq 12$ disc areas, (iii) ETDRS BCVA letter scores of $\geq 19$ and $\leq 69(20 / 400$ to $20 / 40)$, and (iv) submacular hemorrhage or fibrosis within $50 \%$ of entire PED.

The exclusion criteria were (i) anti-VEGF therapy within the past 30 days, (ii) more than one prior PDT session, (iii) treatment of AMD in past 30 days, (iv) any cause of CNV and PED other than AMD, and (v) serous PED without CNV, and (vi) PED with polypoidal choroidal vasculopathy (PCV).

\section{Examination and image acquisition}

ETDRS VA, intraocular pressure, slit-lamp and indirect ophthalmoscopy were obtained monthly. Time-domain
Stratus OCT (Zeiss-Meditec, Fremont, CA, USA) was utilized in all three study sites. Ophthavision Version 3.5 software (Escalon, Ardmore, PA, USA) with a TOPCON TRC-50-IX fundus camera (Topcon, Tokyo, Japan) at one site and with a Zeiss FF450 fundus camera (Zeiss, Oberkochen, Germany) at second site, and the Ophthalmic Imaging Systems Version 11.2.0 software (MediVision Medical Imaging, Yokneam Elit, Israel) with a TOPCON TRC-50EX fundus camera at a third site were utilized for image acquisition for FP, FA, and indocyanine-green (ICG) angiography. Proper reconciliation and adjustment for the different fields of view were made, for valid merging of the data and subsequent analysis.

OCT images were obtained at baseline and repeated monthly. FP and FA were performed at baseline and repeated at months 3, 6, 9 and 12. Additional FP and FA were also obtained for eyes receiving the $2.0 \mathrm{mg}$ dose of ranibizumab at months 1 and 2. ICG angiography was performed at baseline.

The primary endpoint was the mean change from baseline ETDRS BCVA to 12 months. The secondary endpoints included: (i) proportions of eyes with BCVA of $\geq 20 / 200$, (ii) proportion of eyes gaining $\geq 5$ and $\geq 15$ letters from baseline, (iii) decrease in the central 1-mm thickness, (iv) change in OCT (PED height, and central 1-mm, SRF, and CME), (v) FA findings (PED and CNV surface area (SA) and greatest linear diameter (GLD)), (vi) contrast sensitivity, and (vii) performance on Vision Function Questionnaire (VFQ-25) at months 6 and 12 compared with baseline.

The same investigator (CKC) performed measurements of all images. Safety assessments were conducted at baseline and then monthly. PED flattening was defined as collapse of $\geq 90 \%$ of the PED, based on stereoscopic biomicroscopy and OCT assessment.

\section{Statistical analysis}

Both parametric (analysis of variance (ANOVA), paired $t$-tests) and nonparametric statistics ( $\chi^{2}$-analysis, Mann-Whitney, Wilcoxon signed-rank, and Friedman) were utilized for comparisons. A standardized scale $(0=$ none, $1+=$ mild, $2+=$ moderate, and $3+=$ severe $)$ was used to assess ordinal data, that is, cataract, CME and SRF. A $P$-value of $\leq 0.05$ was considered significant. Statistical analyses were performed with Statistical Product and Service Solutions version 20 (IBM Corporation, Armonk, NY, USA).

This study was approved by the Western and UCLA Institutional Review Boards. It conformed to the 1964 Declaration of Helsinki. All study subjects gave full informed consent. This study involved a non-FDAapproved dose of an FDA-approved medication. 


\section{Results}

Of initially enrolled 40 eyes, 4 were excluded from analysis due to type-2 instead of type- 1 CNV in 2, PCV in 1, and study withdrawal for 1 . Thus, 36 eyes (36 patients; Regimen 1: 6 eyes, Regimen 2: 7 eyes, Regimen 3: 12 eyes, Regimen 4: 11 eyes) were analyzed. All patients completed 12 months of follow-up. No differences were found among the four regimens in the baseline characteristics with exception of the mean age (83.1 vs 76 for 0.5 vs $2.0 \mathrm{mg}$ doses) (Table 1 ).

\section{Combined assessment for all study eyes at 12 months}

Vision outcome The Mean baseline BCVA was 0.57 LogMar (20/74), which was significantly worse than the post-RI (month 12) BCVA of 0.46 LogMar (20/58) $(P=0.03)$ (Table 2$)$. There was a mean gain of 4.6 letter scores. There were $88.9 \%$ of study eyes that maintained BCVA of better than or equal to $20 / 200,76.9 \%$ of eyes receiving $0.5 \mathrm{mg}$ and $95.6 \%$ of eyes receiving $2.0 \mathrm{mg}$. There were $83.3 \%$ of eyes in the monthly groups and $94.4 \%$ of eyes in the PRN groups that had a BCVA $\geq 20 / 200$. In addition, $58.3 \%$ of all eyes gained $\geq 5$ ETDRS letters and $30.6 \%$ of eyes gained $\geq 15$ ETDRS.
Anatomical outcome There was a reduction in maximum PED height and central 1-mm subfield thickness compared with baseline (Table 2). There was also a reduction in PED SA and PED GLD $(P<0.001)$ and a reduction in CNV SA and CNV GLD $(P=0.001,0.06)$. Furthermore, there were reductions in SRF and CME $(P<0.001)$.

\section{Comparison of four individual regimens at 12 months}

Vision outcome Post-vs pre-RI comparisons of the four regimens revealed a trend in vision improvement in LogMAR vision, although value was not significant and no difference in the letters gained. There were $50.0 \%$ of eyes in Regimen 1,85.7\% in Regimen 2, $41.7 \%$ in Regimen 3, and $63.6 \%$ in Regimen 4 with a gain of more than five ETDRS letters. There were $33.3 \%$ of eyes in Regimen 1, 42.8\% in Regimen 2, 33.3\% in Regimen 3, and $18.2 \%$ in Regimen 4 with a gain of $\geq 15$ ETDRS letters.

Anatomical outcome Although there were more injections for the monthly eyes (Regimen 1: 11.83 per eye and Regimen 3: 11.7 per eye) than the PRN eyes (Regimen 2: 10 per eye and Regimen 4: 8.55 per eye),

Table 1 Comparison of baseline characteristics of four regimens, $(N=36)$

\begin{tabular}{|c|c|c|c|c|c|}
\hline Baseline variable & $\begin{array}{c}0.5 \text { mg monthly } \\
\text { Mean }(S D) \\
{ }^{a} \text { Median }\end{array}$ & 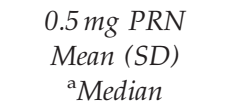 & $\begin{array}{c}2.0 \text { mg monthly } \\
\text { Mean }(S D) \\
{ }^{\mathrm{a}} \text { Median }\end{array}$ & $\begin{array}{c}2.0 m g \text { PRN } \\
\text { Mean (SD) } \\
{ }^{\mathrm{a} M e d i a n}\end{array}$ & $\begin{array}{c}\mathrm{P} \text { values } \\
\text { (entire study group) }\end{array}$ \\
\hline Age & $82.00(6.20)$ & $84.00(6.00)$ & $77.25(6.24)$ & $74.64(9.44)$ & 0.051 \\
\hline Gender & $\begin{array}{c}\text { Male: } 0 \\
\text { Female: } 6\end{array}$ & $\begin{array}{c}\text { Male: } 1 \\
\text { Female: } 6\end{array}$ & $\begin{array}{c}\text { Male: } 5 \\
\text { Female: } 7\end{array}$ & $\begin{array}{c}\text { Male: } 4 \\
\text { Female: } 7\end{array}$ & 0.21 \\
\hline RE vs LE & RE: 3, LE: 3 & RE: 5, LE: 2 & RE: 10, LE: 2 & RE: 6, LE: 5 & 0.38 \\
\hline \multicolumn{6}{|l|}{ Cataract: } \\
\hline Cort & $3.00^{\mathrm{a}}$ & $2.00^{\mathrm{a}}$ & $1.00^{\mathrm{a}}$ & $0^{\mathrm{a}}$ & 0.24 (Cort) \\
\hline NS & 2.00 & 2.00 & 3.00 & 3.00 & 0.02 (NS) \\
\hline PSC & 0 & 0 & 0 & 0 & 0.70 (PSC) \\
\hline SRF & $1.50^{\mathrm{a}}$ & $1.00^{\mathrm{a}}$ & $2.00^{\mathrm{a}}$ & $1.00^{\mathrm{a}}$ & 0.64 \\
\hline $\mathrm{CME}$ & $1.00^{\mathrm{a}}$ & $1.00^{\mathrm{a}}$ & $0^{\mathrm{a}}$ & $0^{\mathrm{a}}$ & 0.15 \\
\hline BCVA (LS) & $54.00(6.63)$ & $53.29(14.35)$ & $61.50(7.21)$ & $58.45(8.35)$ & 0.22 (LS) \\
\hline CNV GLD & $2763.28(602.58)$ & $2790.51(1836.77)$ & $1153.04(751.54)$ & $1858.03(890.12)$ & 0.083 \\
\hline CNV SA & $3.35(1.30)$ & $5.15(4.57)$ & $1.06(1.52)$ & $1.85(1.66)$ & 0.061 \\
\hline PED GLD & $4121.90(437.70)$ & $4372.49(450.46)$ & 4315.29 (1343.04) & 3619.75 (1498.83) & 0.47 \\
\hline Contrast sensitivity & $24.20(5.76)$ & $27.00(3.10)$ & $25.73(7.32)$ & $27.10(5.82)$ & 0.67 \\
\hline PED SA & $9.48(1.35)$ & $12.26(3.72)$ & $11.46(7.52)$ & $8.61(7.07)$ & 0.57 \\
\hline PED height & 375.72 (198.27) & $426.30(149.59)$ & 501.97 (197.71) & 368.83 (145.55) & 0.29 \\
\hline Central 1-mm thickness & $281.17(70.91)$ & 336.57 (113.37) & $311.17(75.01)$ & $297.45(83.74)$ & 0.67 \\
\hline
\end{tabular}

Abbreviations: BCVA, best-corrected visual acuity; CME, cystoid macular edema; CNV, choroidal neovascularization; cort, cortical; GLD, greatest linear diameter; LE, left eye; LS, letter score; NS, nuclear sclerotic; PSC, posterior subcapsular; PRN, pro-re nata; RE, right eye; SA, surface area; SD, standard deviation; SRF, subretinal fluid.

a $\chi^{2}$-analysis used for comparison of gender, RE vs LE, cataract, SRF, and CME. One-way ANOVA used for comparison of age, CNV GLD, CNV SA, PED GLD, PED SA, PED height, and central 1-mm thickness; one-way ANOVA used for the comparison of contrast sensitivity; Kruskal-Wallis Test used for the comparison of VA. 
the differences in the numbers were not great, and the monthly and PRN treatments were equally effective in improving all ocular outcomes; no statistically significant differences were observed between groups.

Two-way ANOVA comparisons of the four regimens revealed significant decreases in post- $v$ s pre-RI maximum PED height $(P<0.01)$ and central $1-\mathrm{mm}$ subfield thickness $(P<0.001)$. There were also significant decreases in post- vs pre-RI PED and CNV SA and PED GLD, and SRF for all four regimens. There was

Table 2 Comparison of baseline with month 12 outcomes for combined study group to ranibizumab $(N=36)$

\begin{tabular}{lccr}
\hline Outcome variable & $\begin{array}{c}\text { Baseline mean } \\
(S D){ }^{\text {a Median }}\end{array}$ & $\begin{array}{c}\text { Month 12 Mean } \\
\left(\text { SD) }{ }^{\mathrm{a}} \text { Median }\right.\end{array}$ & P-value \\
\hline BCVA, LogMAR & $0.57(0.19)$ & $0.46(0.36)$ & 0.04 \\
Contrast sensitivity & $26.16(5.84)$ & $26.75(8.04)$ & 0.54 \\
PED GLD, $\mu \mathrm{m}$ & $4081.65(1172.12)$ & $3116.28(1350.95)$ & $<0.001$ \\
PED SA, mm ${ }^{2}$ & $10.42(6.08)$ & $6.40(4.75)$ & $<0.001$ \\
CNV GLD, $\mu \mathrm{m}$ & $2044.29(1227.84)$ & $1559.86(1179.99)$ & 0.055 \\
CNV SA, mm ${ }^{2}$ & $2.76(3.06)$ & $1.44(2.10)$ & 0.001 \\
PED height, $\mu \mathrm{m}$ & $425.53(176.72)$ & $208.45(153.43)$ & $<0.001$ \\
Central 1-mm & $306.92(83.77)$ & $213.89(56.68)$ & $<0.001$ \\
thickness, $\mu \mathrm{m}$ & & & \\
SRF & $2.00^{\mathrm{a}}$ & $0^{\mathrm{a}}$ & $<0.001$ \\
CME & $1.00^{\mathrm{a}}$ & $0^{\mathrm{a}}$ & $<0.001$ \\
\hline
\end{tabular}

Abbreviations: BCVA, best-corrected visual acuity; CME, cystoid macular edema; GLD, greatest linear diameter; $\log M a r, \operatorname{logarithm}_{10}$ reciprocal of snellen visual acuity equivalent; LS, early treatment diabetic retinopathy study letter scores; PED, pigment epithelial detachment; SA, surface area; $\mathrm{SD}$, standard deviation; SRF, subretinal fluid.

Wilcoxon Signed-Rank test performed for comparison for SRF and CME; Paired Samples significant reduction in CME for Regimens 1 and 2 but not for 3 and 4 . There were no differences in contrast sensitivity for all four regimens.

\section{Comparison of 0.5 vs $2.0 \mathrm{mg}$ of Ranibizumab at 12 months}

Vision outcome The two-way ANOVA comparing the $0.5 \mathrm{mg}$ dose with the $2.0 \mathrm{mg}$ dose showed a significant increase in vision over time within groups $(P=0.05)$ but no difference between groups (Table 3 ). There was a mean gain of 4.3 letters for eyes receiving the $0.5 \mathrm{mg}$ dose, and a mean gain of 4.8 letters for eyes receiving the $2.0 \mathrm{mg}$ dose.

In addition, $53.8 \%$ of $0.5 \mathrm{mg}$ eyes $v \mathrm{~s} 52.2 \%$ of $2.0 \mathrm{mg}$ eyes developed a gain of $>5$ ETDRS letters and $38.5 \%$ of $0.5 \mathrm{mg}$ eyes $v s 26.1 \%$ of $2.0 \mathrm{mg}$ eyes developed a gain of $\geq 15$ ETDRS letters.

Anatomical outcome Statistically significant decreases in mean maximum PED heights were observed in patients receiving $0.5 \mathrm{mg}$ as well as $2.0 \mathrm{mg}$ ranibizumab (Table 3) (Figure 1). There were also statistically significant reductions in mean 1-mm thickness, as well as in PED SA and GLD, and CNV SA, for both the 0.5 and $2.0 \mathrm{mg}$ doses (all $P \leq 0.001$ ).

There was significantly reduced SRF for both 0.5 and $2.0 \mathrm{mg}$ eyes. There was also significantly less CME for the $0.5 \mathrm{mg}$ eyes. Regarding the $2.0 \mathrm{mg}$ eyes, the $P$-value was borderline for the CME comparison.

No statistically significant differences were observed between the 0.5 and $2.0 \mathrm{mg}$ groups for the maximum

Table 3 Comparison of baseline with month 12 outcomes for 0.5 vs $2.0 \mathrm{mg}$ dose of ranibizumab by two-way ANOVA ( $N=36$ )

\begin{tabular}{|c|c|c|c|c|c|}
\hline Outcome variable & Dose (mg) & Baseline mean (SD) & Month 12 mean (SD) & $\begin{array}{c}\text { P-value between } \\
\text { regimens }\end{array}$ & $\begin{array}{l}\text { P-value within } \\
\text { regimen }\end{array}$ \\
\hline \multirow[t]{2}{*}{ PED height, $\mu \mathrm{m}$} & 0.5 & $402.96(168.10)$ & $235.36(153.82)$ & \multirow[t]{2}{*}{0.95} & \multirow[t]{2}{*}{$<0.001$} \\
\hline & 2.0 & $438.30(183.84)$ & $193.24(154.52)$ & & \\
\hline \multirow[t]{2}{*}{ Central 1-mm thickness, $\mu \mathrm{m}$} & 0.5 & $311.00(96.68)$ & $200.38(48.70)$ & \multirow[t]{2}{*}{0.70} & \multirow[t]{2}{*}{$<0.001$} \\
\hline & 2.0 & 304.61 (77.78) & $221.52(60.41)$ & & \\
\hline \multirow[t]{2}{*}{ PED SA $\left(\mathrm{mm}^{2}\right)$} & 0.5 & $10.98(3.12)$ & $7.94(5.00)$ & \multirow[t]{2}{*}{0.35} & \multirow[t]{2}{*}{$<0.001$} \\
\hline & 2.0 & $10.10(7.29)$ & $5.53(4.48)$ & & \\
\hline \multirow[t]{2}{*}{ PED GLD, $\mu \mathrm{m}$} & 0.5 & $4256.83(445.18)$ & $3541.71(1061.11)$ & \multirow[t]{2}{*}{0.22} & \multirow[t]{2}{*}{$<0.001$} \\
\hline & 2.0 & $3982.64(1431.51)$ & $2875.82(1456.70)$ & & \\
\hline \multirow[t]{2}{*}{ CNV SA $\left(\mathrm{mm}^{2}\right)$} & 0.5 & $4.08(3.86)$ & $2.32(2.91)$ & \multirow[t]{2}{*}{0.06} & \multirow[t]{2}{*}{0.001} \\
\hline & 2.0 & $1.65(1.67)$ & $0.70(0.46)$ & & \\
\hline \multirow[t]{2}{*}{ CNV GLD, $\mu \mathrm{m}$} & 0.5 & 2599.32 (1468.19) & $1811.08(1367.71)$ & \multirow[t]{2}{*}{0.11} & \multirow[t]{2}{*}{0.044} \\
\hline & 2.0 & $1581.76(775.25)$ & 1350.51 (1011.17) & & \\
\hline \multirow[t]{2}{*}{ Contrast sensitivity } & 0.5 & $25.73(4.50)$ & $25.18(9.79)$ & \multirow[t]{2}{*}{0.54} & \multirow[t]{2}{*}{0.75} \\
\hline & 2.0 & $26.38(6.5)$ & $27.57(7.09)$ & & \\
\hline \multirow[t]{2}{*}{ BCVA LogMar } & 0.5 & $0.64(0.21)$ & $0.53(0.44)$ & \multirow[t]{2}{*}{0.10} & \multirow[t]{2}{*}{0.05} \\
\hline & 2.0 & $0.52(0.15)$ & $0.41(0.29)$ & & \\
\hline
\end{tabular}

Abbreviations: BCVA, best-corrected visual acuity; CNV, choroidal neovascularization; GLD, greatest linear diameter; LogMar, logarithm 10 reciprocal of snellen visual acuity equivalent; PED, pigment epithelial detachment; SA, surface area; SD, standard deviation. 
a

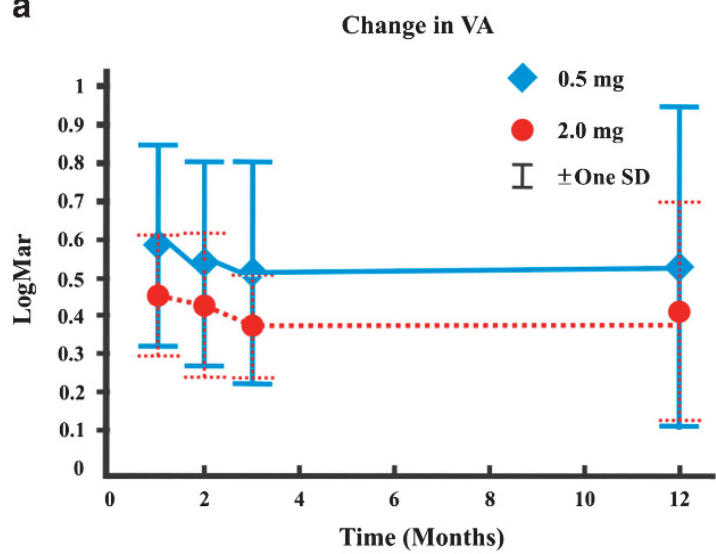

b

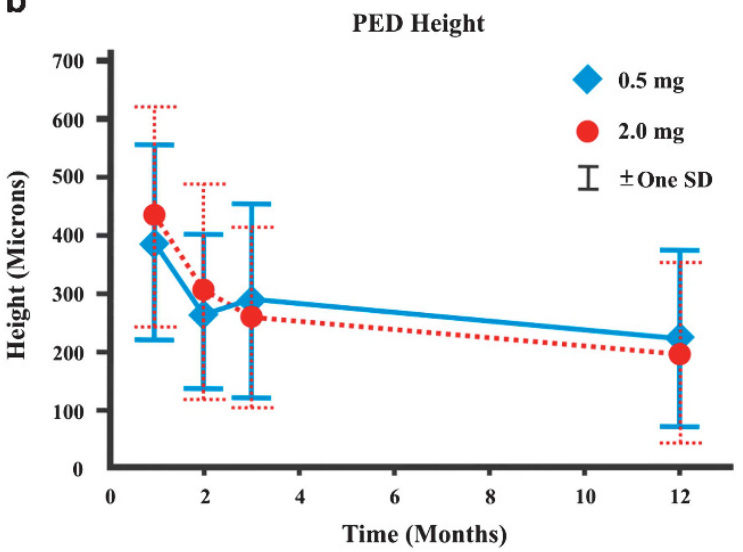

Figure 1 (a) Composite course of best-corrected visual acuities in LogMar equivalent of study eyes over 12 months comparing the $0.5 \mathrm{mg}$ with the $2.0 \mathrm{mg}$ doses, and (b) composite course of pigment epithelial heights of study eyes over 12 months comparing the $0.5 \mathrm{mg}$ with the $2.0 \mathrm{mg}$ doses.

PED height, central 1-mm thickness, PED SA and GLD, and CNV SA and GLD (Table 3).

\section{Contrast sensitivity and VFQ-25 results}

Contrast sensitivity was measured for all eyes at baseline, months 3, 6, 9, and 12. There were no differences in contrast sensitivity comparisons, including the combined cohort, individual four regimens, and 0.5 vs $2.0 \mathrm{mg}$ dose.

VFQ-25 was performed at baseline and repeated at months 6 and 12. The results were divided into (a) distance-visual task scores, (b) near-visual task scores, and (c) composite scores. For baseline comparison, there were no differences in all three categories among the four regimens, and also for 0.5 vs $2.0 \mathrm{mg}$ dose.

(i) Distance- and near-visual task scores: There was improvement in scores for the combined cohort, individual four regimens, and for 0.5 vs $2.0 \mathrm{mg}$ dose at month 12 for both distance and near task scores.

(ii) Composite scores: There was a trend for improvement at month 6 but not at month 12 for the entire combined cohort. There was a lack of differences between month 12 and baseline, between individual regimens and 0.5 vs $2.0 \mathrm{mg}$ dose.

\section{Assessment of early course of treatment}

Vision outcome Early in the course of treatment during weeks 4 and 8, there was a more substantial improvement of vision for eyes receiving $2.0 \mathrm{mg}$ dose in comparison to $0.5 \mathrm{mg}$ dose. For the $2.0 \mathrm{mg}$ group, there was maintenance of visual improvement afterwards (Table 4a).

Anatomical outcome At weeks 4 and 8, there was more substantial decrease in SRF for $2.0 \mathrm{mg}$ dose than
Table 4 Assessment for early response to 0.5 vs $2.0 \mathrm{mg}$ dose of ranibizumab (week 4 and week 8)

\begin{tabular}{|c|c|c|c|c|}
\hline & $\begin{array}{l}\text { P-value } \\
\text { (week 4) }\end{array}$ & \multicolumn{2}{|c|}{$\begin{array}{l}\text { P-value } \\
\text { (week 8) }\end{array}$} & $\begin{array}{c}\text { P-value } \\
\text { (month 12) }\end{array}$ \\
\hline \multicolumn{5}{|c|}{ a. Assessment of early course of vision outcome } \\
\hline $0.5 \mathrm{mg}$ & 0.414 & \multicolumn{2}{|c|}{0.202} & 0.421 \\
\hline $2.0 \mathrm{mg}$ & 0.019 & \multicolumn{2}{|c|}{0.021} & 0.038 \\
\hline \multicolumn{5}{|c|}{ b. Assessment of early course of subretinal fluid reduction } \\
\hline $0.5 \mathrm{mg}$ & 0.058 & & & 0.034 \\
\hline \multirow[t]{2}{*}{$2.0 \mathrm{mg}$} & $<0.001$ & \multicolumn{2}{|c|}{$<0.001$} & 0.414 \\
\hline & $\begin{array}{c}\text { P-value } \\
\text { Pre-treatment } \\
\text { to week } 4\end{array}$ & $\begin{array}{c}\text { P-value } \\
\text { Pre-treatment } \\
\text { to week } 8\end{array}$ & $\begin{array}{l}\text { P-value } \\
\text { (week 8) }\end{array}$ & $\begin{array}{l}\text { P-value } \\
\text { (last visit) }\end{array}$ \\
\hline \multicolumn{5}{|c|}{ c. Assessment of early course of \% reduction in PED reduction } \\
\hline & 0.32 & 0.08 & 0.004 & 0.71 \\
\hline
\end{tabular}

$0.5 \mathrm{mg}$ dose $(P<0.001$ vs 0.058 and $P<0.001$ vs 0.02 , respectively). In contrast, there was reduced absorption of SRF for $2.0 \mathrm{mg}$ dose but greater absorption of SRF for $0.5 \mathrm{mg}$ dose after week $8(P=0.41$ vs 0.03 at month 12$)$, likely due to resolution of most of the SRF by week 8 for $2.0 \mathrm{mg}$ dose (Table $4 \mathrm{~b}$ ).

There was greater percentage reduction in percentage of PED height for $2.0 \mathrm{mg}$ dose than $0.5 \mathrm{mg}$ dose during the early course (Table 4c). For the $2.0 \mathrm{mg}$ dose, most of the reduction in the PED height developed between weeks 4 and 8 .

There were no differences in the percentage reduction in the central $1-\mathrm{mm}$ thickness for the $2.0 \mathrm{mg}$ dose $v s$ $0.5 \mathrm{mg}$ dose during the early course and from baseline to month 12. There were also no differences in percent decrease for pre-treatment to week 12 and week 12 to last visit for PED GLD and CNV SA. 
Monthly os PRN treatments There were no differences between the monthly and the PRN RI regimens for all visual and anatomical outcomes during the early course.

\section{Extent of clinical flattening of PED}

Although the mean maximum PED heights were similar, there were significantly more eyes on $2.0 \mathrm{mg}$ dose observed to have developed $\geq 90 \%$ flattening of the PED in comparison to eyes on $0.5 \mathrm{mg}$ dose at 12 months (77.3 vs $22.7 \%, P=0.036)$.

\section{Adverse events}

There were no substantial changes in cataract development except in one eye in the $0.5 \mathrm{mg}$ monthly arm. When comparing the $0.5 \mathrm{mg}$ with $2.0 \mathrm{mg}$ eyes, there were no significant changes for cortical, nuclear sclerotic, and posterior subcapsular cataracts at 12 months.

An RPE tear developed in four eyes with $2.0 \mathrm{mg}$ dose and in one eye with $0.5 \mathrm{mg}$ dose (13.9\%). The mean baseline PED size (PED height, SA, and GLD) was significantly greater for eyes that developed RPE tears. There was no significant difference in the mean visual acuities between the two groups at baseline; however, the visual outcome was significantly worse for eyes that developed RPE tears at 12 months. ${ }^{20}$ The details relating to the RPE tears in this study are described at length in a prior publication. ${ }^{20}$ In that report, eyes with a maximum PED height $>550 \mu \mathrm{m}$ at baseline were associated with marked increased risk for RPE tears. ${ }^{20}$

\section{Discussion}

The treatment of vPED due to AMD remains a challenging task. Recent studies have shown variable outcomes associated with anti-VEGF therapy for this condition. ${ }^{1,6-19}$ In 2012, Introini et al ${ }^{13}$ studied 132 eyes with vPED or retinal angiomatous proliferation lesions treated with PDT, PDT and intravitreal corticosteroid (IVT), or anti-VEGF therapy over 10 years. At 12 months after treatment, there was marked worsening of vision for eyes treated with PDT or PDT and IVT, and mild decreased vision for eyes treated with anti-VEGF injections despite favorable anatomic outcomes. Baba et $\mathrm{al}^{14}$ reported that of 37 eyes receiving anti-VEGF therapy, there were no changes in visual outcome in eyes with avascular PED but decreased vision in eyes with vPED or PCV despite similar improvement in PED heights at 2 years. On the other hand, Inoue et al ${ }^{15}$ reported visual stabilization despite no anatomical correlation after treatment of 56 eyes with PED due to AMD at 12 months. They also found that eyes with avascular PED responded better than eyes with fibrovascular or hemorrhagic PED. Veritte et al ${ }^{16}$ found similar results with ranibizumab treatment of 40 eyes with vPED. Chan et al ${ }^{17}$ also reported rapid resolution of fluid, hemorrhage, and flattening of the PED with stable vision in selected eyes treated with high dose ranibizumab.

Our current study shows that when considering the entire study cohort, there was significant visual improvement and reduction in mean central 1-mm thickness, maximum PED height, SA and GLD, and CNV $\mathrm{SA}$, and reduction of SRF and CME. Our results are consistent with the HARBOR Study. ${ }^{12}$ Similar to HARBOR, our study shows comparable overall improvements in letter scores and reductions in PED height for both 0.5 and $2.0 \mathrm{mg}$ doses. There was a mean gain of 4.3 letters for eyes receiving the $0.5 \mathrm{mg}$ dose and a mean gain of 4.8 letters for eyes receiving the $2.0 \mathrm{mg}$ dose at 12 months. This is in contrast to a mean gain ranging from 8.2 to 10.1 letters for the $0.5 \mathrm{mg}$ dose and a mean gain ranging from 8.6 to 9.2 letters for the $2.0 \mathrm{mg}$ dose at 12 months in HARBOR. Regarding mean reductions in central subfield thickness, there were mean reductions of 97.0 and $122.3 \mu \mathrm{m}$ for eyes receiving the $0.5 \mathrm{mg}$ dose, and mean reductions of 109.8 and $53.9 \mu \mathrm{m}$ for eyes receiving the $2.0 \mathrm{mg}$ dose in our study. In contrast, there were mean reductions of $172.0 \mu \mathrm{m}$ and $161.2 \mu \mathrm{m}$ for the former and mean reductions of $163.3 \mu \mathrm{m}$ and $172.4 \mu \mathrm{m}$, respectively, for the latter at 12 months in HARBOR. Various subtypes of exudative AMD besides vPED were included in HARBOR. Therefore, the lower magnitudes of mean letters gained and central subfield thickness reductions in our study in comparison to HARBOR are consistent with the more resistant nature of vPED to anti-VEGF therapy.

The greater total numbers of injections per eye in our study compared with HARBOR at 12 months (9.6-10 vs 6.9-7.7) are also consistent with more resistant nature of vPED to anti-VEGF therapy.

Despite similar vision and anatomical outcomes at 12 months when comparing 0.5 with $2.0 \mathrm{mg}$ doses, the visual improvement occurred much earlier in the course of treatment for $2.0 \mathrm{mg}$ dose in comparison to $0.5 \mathrm{mg}$ dose (Table 4a, Figure 1), which is a new pertinent finding not reported previously. There was also a rapid resolution of most of the SRF early in the course of treatment so that only very little fluid remained for absorption after 8 weeks for $2.0 \mathrm{mg}$ dose. In contrast, there was a more gradual course of absorption of SRF for $0.5 \mathrm{mg}$ dose (Table 4b). Similarly, there was a greater percentage reduction of maximum PED height for $2.0 \mathrm{mg}$ dose early in the course of treatment in comparison to $0.5 \mathrm{mg}$ dose (Table 4c). Despite similar magnitudes of decrease in mean maximum PED heights at 12 months for both the 0.5 and $2.0 \mathrm{mg}$ doses, clinical assessment showed a 
greater percentage of $2.0 \mathrm{mg}$ dose with more complete flattening of the PED.

Regarding the safety profile, there were few ocular adverse events and no systemic adverse outcomes. There were no differences in cataract progression between the 0.5 and $2.0 \mathrm{mg}$ doses. However, three eyes in the $2.0 \mathrm{mg}$ group while only one eye in the $0.5 \mathrm{mg}$ group developed an RPE tear. It is possible that the more rapid visual and anatomic gains associated with the $2.0 \mathrm{mg}$ dose may have occurred at the price of an increased risk for RPE tears due to more vigorous contraction of the $\mathrm{CNV}$ under the PED following the injection of the $2.0 \mathrm{mg}$ dose. Multiple reports have implicated the contribution of contractile forces of type-1 CNV under a PED to the mechanism of RPE tear development. ${ }^{20-26}$ One spectral-domain OCT study showed that rapid and vigorous contraction of the neovascular tissue adherent to the undersurface of the RPE may impart a substantial contractile force for tearing the already-strained RPE. ${ }^{27}$ Multiple reports have also documented retinal tears and detachment induced by contraction of fibrovascular tissues after anti-VEGF injections in eyes with proliferative diabetic retinopathy. ${ }^{28-30}$ Consistent with previous reports, ${ }^{17-19}$ our study shows that the mean PED dimensions at baseline were significantly higher for eyes that developed RPE tears in comparison to those without RPE tears. In contrast, head-to-head comparison of baseline characteristics between 2.0 and $0.5 \mathrm{mg}$ eyes failed to show significant differences (including PED dimensions) (Table 1). One eye receiving the $2.0 \mathrm{mg}$ dose with an RPE tear had a PED height of less than $400 \mu \mathrm{m}$ at baseline. Thus, higher dose besides increased PED dimensions may also contribute to the risk for RPE tears. However, we caution against a firm conclusion regarding such a risk associated with $2.0 \mathrm{mg}$ dose, given the small overall number of RPE tears in this study.

Besides BCVA, we documented improvements in distance- and near-visual task scores with VFQ-25 testing for the entire cohort. Similar to the BCVA changes, there were no differences in these improvements at month 12 when comparing the four individual regimens and when contrasting the $0.5 \mathrm{mg}$ with the $2.0 \mathrm{mg}$ dose. The reason for the lack of similar improvements in the composite scores is unknown, but it may be related to the lack of sufficient sample size.

The strengths of this study include a prospective design, standardized vision measurement, close followup and multimodal imaging by experienced personnel, and careful measurements of all images with uniform methodology by same investigator. This study corroborated the benefit of ranibizumab in enhancing daily distance and near-visual tasks encountered by patients with vPED whether given with monthly or PRN regimen or at conventional or high dose. The small sample size and time- instead of spectral-domain OCT are limitations of this study. At onset of this study, timedomain OCT was the standard imaging instrument. In addition, time-domain technology provided sufficiently accurate measurements for the purpose of this study and spectral-domain OCT would likely not have changed the results. The qualitative methodology for assessing cataract, SRF, and CME likely needs further validation. Despite these limitations, pertinent findings of clinical relevance are revealed.

In conclusion, both 0.5 and $2.0 \mathrm{mg}$ intravitreal ranibizumab induced similar overall visual and anatomic improvements at 12 months. Significantly, the improvements occurred much earlier for the $2.0 \mathrm{mg}$ dose group. To achieve more rapid visual and anatomical improvements in treating vPED associated with AMD, one may consider utilizing a higher dose of ranibizumab. However, the trade-off is a possible increased tendency for an RPE tear associated with the higher dose, particularly for eyes with a vPED of larger dimensions.

\section{Summary}

What was known before

- Vascularized PED is known to be a particularly difficult form of exudative AMD to treat, including anti-VEGF therapy.

- A prior study (HARBOR Trial) has shown comparable final visual and anatomic outcomes between 0.5 and $2.0 \mathrm{mg}$ dose of ranibizumab in treatment of eyes with exudative AMD.

What this study adds

- A greater percentage of eyes with vascularized PED receiving the $2.0 \mathrm{mg}$ dose of ranibizumab developed more complete flattening of the PED.

- Although this study shows comparable final visual and anatomic results for 0.5 and $2.0 \mathrm{mg}$ doses of ranibizumab in treatment of vascularized PED due to AMD, vision improvement, and SRF and PED height reductions occurred much earlier with the $2.0 \mathrm{mg}$ dose in comparison to the $0.5 \mathrm{mg}$ dose.

\section{Conflict of interest}

This Investigator Initiated Study has received grant supports from Roche-Genentech Inc., Owen Locke Foundation, and Kirchgessner Foundation. The authors have no financial or proprietary interest in any device or drug mentioned in this study.

\section{Acknowledgements}

We thank Grenith Zimmerman, PhD of the School of Allied Health Professions at the Loma Linda University for the performance of the statistical analyses. This study was registered with ClinicalTrials.Gov. (NCT00749021). 


\section{References}

1 Chan CK, Meyer CH, Gross JG, Abraham P, Nuthi AS, Kokame GT et al. Retinal pigment epithelial tears after intravitreal bevacizumab injection for neovascular agerelated macular degeneration. Retina 2007; 27: 541-551.

2 Chuang EL, Bird AC. The pathogenesis of tears of the retinal pigment epithelium. Am J Ophthalmol 1988; 105: 285-290.

3 Pauleikoff D, Löffert D, Spital G, Radermacher M, Dohrmann J, Lommatzsch A et al. Pigment epithelial detachment in the elderly. Clinical differentiation, natural course and pathogenetic implications. Graefes Arch Clin Exp Ophthalmol 2002; 240: 533-538.

4 Mrejen S, Sarraf D, Mukkamala SK, Freund KB. Multimodal imaging of pigment epithelial detachment: a guide to evaluation. Retina 2013; 33: 1735-1762.

5 The Moorfields Macular Study Group. Retinal pigment epithelial detachments in the elderly: a controlled trial of argon laser photocoagulation. Br J Ophthalmol 1982; 66: 1-16.

6 Audrey L, Arnaud C, Fournie P, Mathis A, Quintyn JC. Combined photodynamic therapy with verteporfin and intravitreal triamcinolone acetonide for choroidal neovascularization with pigment epithelium detachment in age-related macular degeneration [in French]. J Fr Ophtalmol 2007; 30: 155-160.

7 Chen E, Kaiser RS, Vander JF. Intravitreal bevacizumab for refractory pigment epithelial detachment with occult choroidal neovascularization in age-related macular degeneration. Retina 2007; 27: 445-450.

8 Chan CK, Lin SG. Retinal pigment epithelial tear after ranibizumab therapy for subfoveal fibrovascular pigment epithelial detachment. Eur J Ophthalmol 2007; 17: 674-676.

9 Brown DM, Kaiser PK, Michels M, Soubrane G, Heier JS, Kim RY et al. Ranibizumab versus verteporfin for neovascular age-related macular degeneration. $N$ Engl J Med 2006; 355: 1432-1444.

10 Rosenfeld PJ, Brown DM, Heier JS, Boyer DS, Kaiser PK, Chung CY et al. Ranibizumab for neovascular age-related macular degeneration. N Engl J Med 2006; 355: 1419-1431.

11 Boyer DS, Antoszyk AN, Awh CC, Bhisitkul RB, Shapiro H, Acharya NR et al. Subgroup analysis of the MARINA study of ranibizumab in neovascular age-related macular degeneration. Ophthalmology 2007; 114: 235-252.

12 Busbee BG, Ho AC, Brown DM, Heier JS, Suñer IJ, Li Z et al. Twelve-month efficacy and safety of $0.5 \mathrm{mg}$ or $2.0 \mathrm{mg}$ ranibizumab in patients with subfoveal neovascular agerelated macular degeneration. Ophthalmology 2013; 120: 1046-1056.

13 Introini U, Torres Gimeno A, Scotti F, Setaccioli M, Giatsidis S, Bandello F. Vascularized retinal pigment epithelial detachment in age-related macular degeneration treatment and RPE tear incidence. Graefes Arch Clin Exp Ophthalmol 2012; 250: 1283-1292.

14 Baba T, Kitahashi M, Kubota-Taniai M, Oshitari T, Yamamoto S. Two-year course of subfoveal pigment epithelial detachment in eyes with age-related macular degeneration and visual acuity better than 20/40. Ophthalmologica 2012; 228: 102-109.

15 Inoue M, Arakawa A, Yamane S, Kadonosono K. Variable response of vascularized pigment epithelial detachments to ranibizumab based on lesion subtypes, including polypoidal choroidal vasculopathy. Retina 2013; 33: 990-997.
16 Veritti D, Macor S, Menchini F, Lanzetta P. Effects of VEGF inhibition on retinal morphology, neovascular network size, and visual acuity in patients with vascularized pigment epithelium detachment because of occult choroidal neovascularization. Retina 2013; 33: 982-989.

17 Chan CK, Abraham P, Sarraf D. High-dose ranibizumab therapy for vascularized pigment epithelial detachment. Eye 2012; 26: 882-885.

18 Chiang A, Chang LK, Yu F, Sarraf D. Predictors of antiVEGF-associated retinal pigment epithelial tear using FA and OCT analysis. Retina 2008; 28: 1265-1269.

19 Chan CK, Abraham P, Meyer CH, Kokame GT, Kaiser PK, Rauser ME et al. Optical coherence tomography-measured pigment epithelial detachment height as a predictor for retinal pigment epithelial tears associated with intravitreal bevacizumab injections. Retina 2010; 30: 203-211.

20 Sarraf D, Chan C, Rahimy E, Abraham P. Prospective evaluation of the incidence and risk factors for the development of RPE tears after high-and low-dose ranibizumab therapy. Retina 2013; 33: 1551-1557.

21 Spaide RF. Enhanced depth imaging optical coherence tomography of retinal pigment epithelial detachment in age-related macular degeneration. Am J Ophthalmol 2009; 147: 644-652.

22 Sato T, Kishi S, Watanabe G, Matsumoto H, Mukai R. Tomographic features of branching vascular networks in polypoidal choroidal vasculopathy. Retina 2007; 27: 589-594.

23 Khan S, Engelbert M, Imamura Y, Freund KB. Polypoidal choroidal vasculopathy: simultaneous indocyanine green angiography and eye-tracked spectral domain optical coherence tomography findings. Retina 2012; 32: 1057-1068.

24 Toth CA, Pasquale 3rd AC, Graichen DF. Clinicopathologic correlation of spontaneous retinal pigment epithelial tears with choroidal neovascular membranes in age-related macular degeneration. Ophthalmology 1995; 102: 272-277.

25 Lafaut BA, Aisenbrey S, Vanden Broecke C, Krott R, Jonescu-Cuypers CP, Reynders $\mathrm{S}$ et al. Clinicopathological correlation of retinal pigment epithelial tears in exudative age related macular degeneration: pretear, tear, and scarred tear. Br J Ophthalmol 2001; 85: 454-460.

26 Clemens CR, Bastian N, Alten F, Milojcic C, Heiduschka P, Eter N. Prediction of retinal pigment epithelial tear in serous vascularized pigment epithelium detachment. Acta Ophthalmol 2014; 92: 50-56.

27 Nagiel A, Freund B, Spaide RF, Munch IC, Larsen M, Sarraf D. Mechanism of retinal pigment epithelium tear formation following intravitreal anti-vascular endothelial growth factor therapy revealed by spectral-domain optical coherence tomography. Am J Ophthalmol 2013; 156: 981-988.

28 Arevalo JF, Maia M, Flynn Jr HW, Saravia M, Avery RL, $\mathrm{Wu} \mathrm{L}$ et al. Tractional retinal detachment following intravitreal bevacizumab (Avastin) in patients with severe proliferative diabetic retinopathy. Br J Ophthalmol 2008; 92: 213-216.

29 Mitamura Y, Ogata K, Oshitari T, Asaumi N, Yamamoto S. Retinal detachment with macular hole following intravitreal bevacizumab in patient with severe proliferative diabetic retinopathy. Br J Ophthalmol 2008; 92: 717-718.

30 Yeh PT, Yang CM, Lin YC, Chen MS, Yang CH. Bevacizumab pretreatment in vitrectomy with silicone oil for severe diabetic retinopathy. Retina 2009; 29: 768-774. 